\title{
Efficacy of intranasal fluticasone propionate and budesonide in management of allergic rhinitis - a prospective comparative study
}

\author{
P. Kiruba Shankari ${ }^{1}$, Swathi Suresh ${ }^{2}$ and Rukaiah Fatma Begum ${ }^{2^{*}}$
}

\begin{abstract}
Background: Allergic rhinitis (AR) or Hay fever is a chronic inflammation of the nasal mucosa induced by lgE-mediated hypersensitivity due to exposure of various allergens. AR occurs as a response against these inhaled allergens that cause inflammation of nasal mucosal membranes. In this study, a reliable treatment for allergic rhinitis with maximum effectiveness and minimal side effects was assessed. This study compared the effectiveness of intranasal Fluticasone propionate (FUP) and intranasal Budesonide (BUD) in reducing the eosinophil count and in improving the nasal and ocular symptoms. This prospective study was conducted on 62 cases of allergic rhinitis and patients with mild-to-moderate allergic rhinitis were selected for the study. They were randomly divided into two groups; group I consists of 30 patients who received intranasal Fluticasone propionate aqueous spray, total daily dose of $200 \mu \mathrm{g}$ $(50 \mathrm{\mu g} / \mathrm{spray})$ as 2 sprays in each nostril administered once daily, whereas the group II consists of 32 patients who received intranasal Budesonide aqueous spray, total daily dose of $400 \mu \mathrm{g} /$ day $(100 \mu \mathrm{g} / \mathrm{spray})$ as 1 spray in each nostril administered twice daily.

Results: Analysis on patient-based symptom scores revealed that both the groups showed statistically significant reduction in symptoms. Fluticasone propionate was found to be significantly more effective $(P<0.05)$ than Budesonide in reducing sneezing, nasal itching and majority of symptoms of individual symptom scores. Budesonide showed somewhat similar effect in reducing nasal blockage at 4 weeks of treatment.
\end{abstract}

Conclusion: Clinically, both the drugs showed statistically significant improvement when compared to baseline, but Fluticasone propionate was superior at reducing nasal symptoms, ocular symptom and eosinophil count.

Keywords: Allergic rhinitis, Visual analogue scale, Absolute eosinophil count, Fluticasone propionate, Budesonide, Intranasal corticosteroids

\section{Background}

Allergic rhinitis (AR) or hay fever is a chronic inflammation of nasopharynx that occurs as a response against inhaled allergen exposure triggered by immunoglobulin $\mathrm{E}$ (IgE)-mediated inflammation of nasal membranes [1-3]. Allergic rhinitis is a symptomatic disorder triggered after inhalation of allergens such as house dust, mites, pollens,

\footnotetext{
*Correspondence: rukaiah786@gmail.com

${ }^{2}$ Department of Pharmacology, SRM College of Pharmacy, SRM Institute of Science, and Technology, Kattankulathur, Chennai, Tamil Nadu, India Full list of author information is available at the end of the article
}

animal danders (cat and dog allergens, rodent), fungal, molds, yeast, insects and other allergens $[4,5]$. The nasal symptoms include nasal congestion, rhinorrhea, sneezing and nasal itching, whereas ocular symptoms include watery eyes, burning, redness and itching eyes [6]. Allergic rhinitis was classified into three types; they are seasonal allergic rhinitis, perennial allergic rhinitis and episodic allergic rhinitis [7].

Allergens in the environment can synthesize allergen-specific immunoglobulin $\mathrm{E}$ production which interacts with B cells, $\mathrm{T}$ cells, mast cells, basophil and starts accumulation in nasal mucosa which involves a 
pathophysiology of allergic rhinitis and asthma. This receptor-bound accumulation due do exposure of allergens leads to the production of mediators such as histamines, leukotriene and other mediators that shows allergic responses as nasal and ocular symptoms [8]. To identify the allergens is an important step for diagnosis of allergic rhinitis, allergen avoidance and allergen-specific immunotherapy [9].

In the current standard, intranasal corticosteroids are best and effective first-line therapy recommended for allergic rhinitis in preventing and relieving nasal and ocular symptoms. In allergic process, corticosteroids have a major role in reducing mediators and inflammatory cells [10]. Most commonly, corticosteroids are used as nasal sprays to treat allergic rhinitis but in patients with moderate to severe symptoms, systemic treatment may be used [11]. In this study, we have conducted an observational study to compare the safety and efficacy of intranasal fluticasone propionate and intranasal budesonide in allergic rhinitis patients. Efficacy was assessed using visual analogue scale for total nasal and ocular symptoms [12]. Fluticasone propionate stimulates glucocorticoid receptors and has potent anti-inflammatory activities, which acts on inflammatory mediators responsible for inflammatory symptoms of allergic rhinitis [13]. Budesonide also has potent antiinflammatory activity and reduces the hyper-reactivity of airways. Budesonide relieves symptoms caused by hay fever or other allergies [14].

In this study, a reliable treatment for allergic rhinitis with maximum effectiveness and reducing the risk of developing allergic asthma was assessed.

\section{Methods}

Patient selection

This clinical prospective observational comparative study includes 62 patients who were diagnosed with allergic

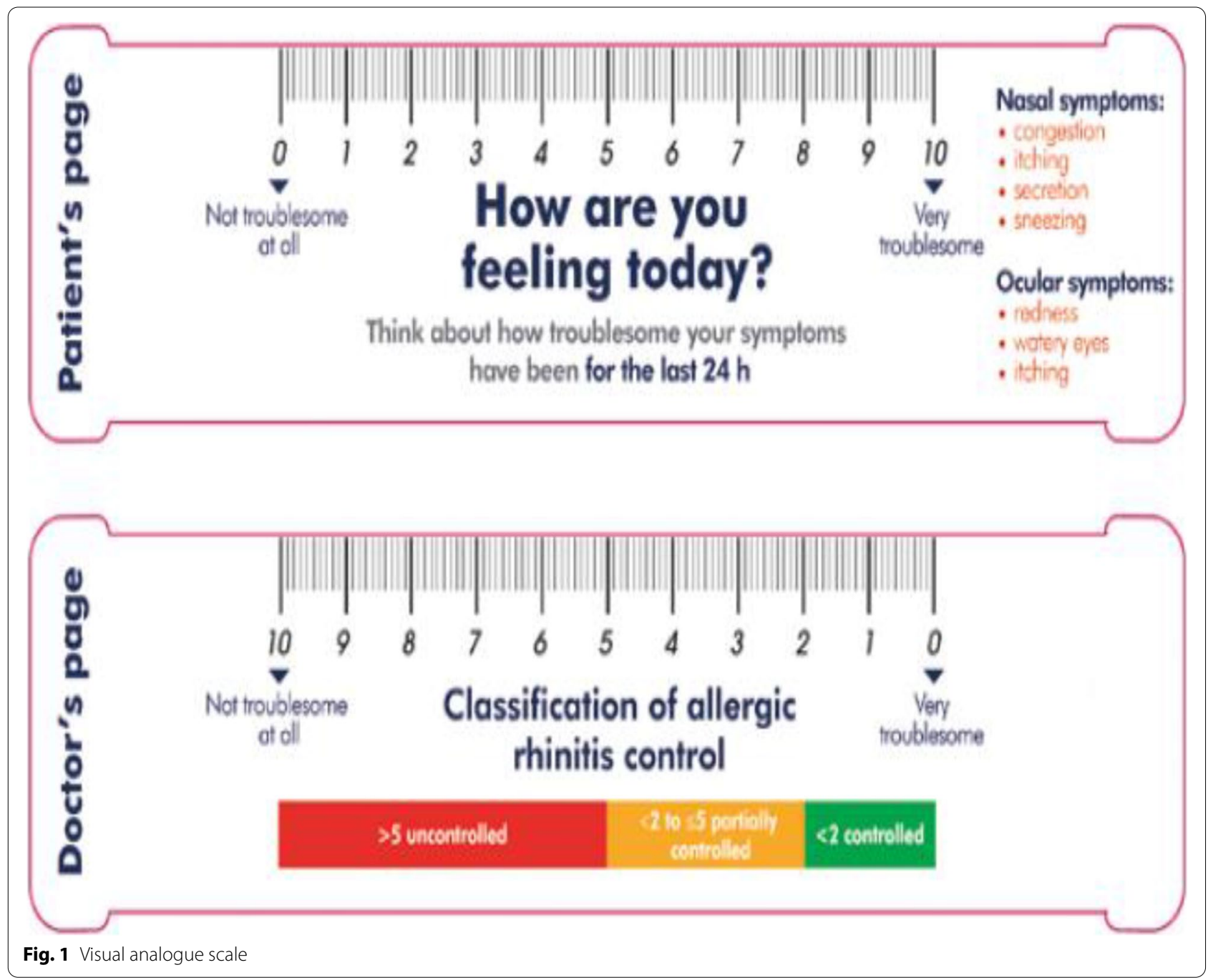


rhinitis and they were randomly assigned into two groups conducted in ENT department, tertiary care hospital in Chennai, Tamil Nadu.

\section{Inclusion criteria}

Patients aged 12 years and above diagnosed with the history of moderate to severe seasonal or perennial allergic rhinitis have symptoms like nasal itching, congestion, rhinorrhoea, sneezing and ocular redness, itching and watery due to rhinitis and have allergy to any of thesehouse mites, pollen, dust, animal dander, dairy products, molds, etc.--were included in the study. Diagnosis was based upon symptoms according to criteria proposed in the International Consensus of Rhinitis.

\section{Exclusion criteria}

Patients suffering from upper or lower respiratory tract infection within the last 1 month prior to enrolment or those who received systemic or topical corticosteroids, herbal drugs, beta blocking agent within the previous month of enrolment, patients with asthma and COPD, nasal bleeding, obstructing nasal polyps, paranasal sinuses and pregnant women were excluded from the study.

This study was carried out in a tertiary care "ESIC Hospital" located at Chennai. The study protocol was explained to all subjects prior to enrolment which has been approved by institutional review board or ethics committee. Informed consent was obtained from the patients with proper information explained as per the Declaration of Helsinki. Patients' details were collected (age, gender and past medical history) by interviewing the patient directly or through patient's medical record to avoid confounding variables. Allergens which caused the allergic rhinitis was diagnosed by two main allergy tests such as the skin prick test in which the allergen is kept on surface of skin and pricked with a needle to know the substance which is allergic to patients and other is blood test to check the immunoglobulin (IgE) antibody in the blood to diagnose allergy.

The patients who were diagnosed with allergic rhinitis were randomly assigned into two groups; the first group (group I) received intranasal Fluticasone propionate aqueous spray (Flonase) with a total daily dose of $200 \mu \mathrm{g}(50 \mu \mathrm{g} / \mathrm{spray})$ as 2 sprays in each nostril administered once daily for 8 weeks. The second group (group II) received intranasal Budesonide aqueous spray (Budenase AQ) with a total daily dose of $400 \mu \mathrm{g} /$ day $(100 \mu \mathrm{g} /$ spray $)$ as 1 spray in each nostril administered twice daily for 8 weeks. The Eosinophil count, visual analogue total nasal symptom scores (VATNSS) and visual analogue total ocular symptom scores (VATOSS) were obtained from the patients to assess the reduction in severity of the symptoms, and the patients were reviewed at 4 th and 8 th week of the treatment. Patients were asked to review at 1-month interval to refill the prescription. The response to the intranasal steroids treatment was monitored by eosinophil count and visual analogue scale (VAS) assessment. The mean difference between baseline, 4th and 8th week of all the parameters were calculated and statistically analyzed.

\section{Visual analogue scale}

Visual analogue scale for nasal and ocular symptoms can be measured using a horizontal scale having numbers from 0 to 10 with descriptions at its ends representing two extremes of feeling. Allergic rhinitis patients were asked to mark a point at the scale as per the severity of a single symptom or current status of disease control at baseline, 4th and 8th week of treatment for all the symptoms (Fig. 1) [15, 16]. The advantages of this scale are high resolution (minimal difference in disease severity can be distinguished), preferred by patients, reproducibility, uniform system of interpretation, routine use, linear scale, well suited for continuous features like AR symptoms, confirmed reliability and accuracy.

\section{Statistical analysis}

Statistical analysis was performed by using the statistical software Graph Pad Prism with 95\% confidence interval. Patient's demographic characteristics analysis was done

Table 1 Baseline clinical characteristics of patients with allergic rhinitis (AR)

\begin{tabular}{lll}
\hline Characteristics & Group I $(\boldsymbol{n}=\mathbf{3 0})$ & Group II $(\boldsymbol{n}=\mathbf{3 2})$ \\
\hline Age & $37.1 \pm 14.0$ & $38.6 \pm 12.9$ \\
Male & $12(40 \%)$ & $11(34.4 \%)$ \\
Female & $18(60 \%)$ & $21(65.6 \%)$ \\
IgE IU/mL & $417 \pm 79.92$ & $432 \pm 71.45$ \\
VATNSS & & \\
$\quad$ Nasal congestion & $8.18 \pm 1.25$ & $8.50 \pm 1.11$ \\
$\quad$ Rhinorrhea & $7.32 \pm 1.51$ & $7.32 \pm 1.72$ \\
$\quad$ Sneezing & $9.06 \pm 0.78$ & $9.27 \pm 0.69$ \\
$\quad$ Nasal Itching & $8.69 \pm 1.24$ & $8.08 \pm 1.41$ \\
VATOSS & & \\
$\quad$ Watery eyes & $7.59 \pm 1.51$ & $7.30 \pm 1.53$ \\
Redness & $7.78 \pm 1.54$ & $7.47 \pm 1.55$ \\
Burning & $6.90 \pm 1.40$ & $6.60 \pm 1.39$ \\
Itching eyes & $6.73 \pm 1.42$ & $6.65 \pm 1.60$ \\
Eosinophil count cells/mcL & $917.06 \pm 249.14$ & $904.37 \pm 244.79$ \\
\hline
\end{tabular}

VATNSS Visual Analogue Total Nasal Symptom score, VATOSS Visual Analogue Total Ocular Symptom Score

Data are shown as mean \pm standard deviation or number (\%) as appropriate. Unpaired $T$ test was used to determine significance 
Table 2 Efficacy outcomes of visual analogue total nasal symptom scores

\begin{tabular}{lllll}
\hline Characteristics & & FUP $(\boldsymbol{n}=\mathbf{3 0})$ & BUD $(\boldsymbol{n}=\mathbf{3 2})$ & $\boldsymbol{P}$ value \\
\hline VATNSS & & & & \\
$\begin{array}{c}\text { Nasal conges- } \\
\text { tion }\end{array}$ & Baseline & $8.18 \pm 1.25$ & $8.50 \pm 1.11$ & 0.29 \\
& 4th week & $6.54 \pm 1.35$ & $6.27 \pm 1.07$ & 0.3 \\
& 8th week & $4.9 \pm 1.23$ & $4.21 \pm 1.07$ & 0.02 \\
Rhinorrhea & P value & $<\mathbf{0 . 0 0 0 1}$ & $<\mathbf{0 . 0 0 0 1}$ & \\
& Baseline & $7.32 \pm 1.51$ & $7.32 \pm 1.72$ & 0.99 \\
& 4th week & $5.23 \pm 1.39$ & $6.14 \pm 1.63$ & 0.02 \\
& 8th week & $3.28 \pm 1.28$ & $4.93 \pm 1.54$ & $<0.0001$ \\
Sneezing & P value & $<\mathbf{0 . 0 0 0 1}$ & $<\mathbf{0 . 0 0 0 1}$ & \\
& Baseline & $9.06 \pm 0.78$ & $9.27 \pm 0.69$ & 0.26 \\
& 4th week & $6.42 \pm 0.93$ & $8.05 \pm 0.71$ & $<0.0001$ \\
& 8th week & $4.05 \pm 0.62$ & $6.82 \pm 0.78$ & $<0.0001$ \\
& P value & $<\mathbf{0 . 0 0 0 1}$ & $<\mathbf{0 . 0 0 0 1}$ & \\
Itching & Baseline & $8.69 \pm 1.24$ & $8.08 \pm 1.41$ & 0.07 \\
& 4th week & $6.03 \pm 1.19$ & $6.76 \pm 1.47$ & 0.03 \\
& 8th week & $3.83 \pm 1.33$ & $5.32 \pm 1.48$ & $<0.0001$ \\
& P value & $<0.0001$ & $<0.0001$ & \\
\hline
\end{tabular}

Data are shown as mean \pm standard deviation as appropriate. Unpaired $T$ test was used to determine significance

VATNSS Visual Analogue Total Nasal Symptom Score, FUP Fluticasone propionate, BUD Budesonide

using MS Excel worksheet. Unpaired $T$ test was used to evaluate mean change in VATNSS, VATOSS and Eosinophil count at baseline, 4 weeks and 8 weeks interval and to determine the significance. $P$ value less than or equal to 0.05 was considered as statistically significant. One-way analysis of variance (ANOVA) was used in this study to assess the comparison of symptoms in both the groups.

\section{Results}

Baseline clinical characteristics

Sixty-two patients were enrolled in the study as per inclusion criteria and randomly assigned into 2 groups. Random assignment of 30 patients to intranasal fluticasone propionate taken as group I and 32 patients to intranasal budesonide taken as group II and these subjects completed the follow up of 8 weeks period. Demographics and baseline characteristics of 62 patients were noted and evaluated for primary and secondary parameters for 8 weeks baseline; clinical characteristics of patients were comparable values between the groups.

In the first group, 12 male (40\%) and 18 female (60\%) patients, their mean age was $37.1 \pm 14.0$ years and in the second group, 11 male (34.4\%) and 21 female (65.6\%) patients and their mean age was $38.6 \pm 12.9$ years. The mean and standard deviation (sd) of demographic parameters at baseline did not show any statistically significant difference (Table 1).

\section{Clinical efficacy}

A total of 30 patients in group I and 32 patients in group II were evaluable and included in the efficacy analysis. Parameters considered in efficacy analysis were visual analogue total nasal symptom scores (VATNSS), visual analogue total ocular symptom scores (VATOSS) and Absolute eosinophil counts.

All the primary and secondary parameters showed statistically significant reduction in severity of symptoms in 8 weeks, proving clinical improvement in both the groups. However, group I showed statistical improvement of disease progression and reduction in severity of symptoms and eosinophil count.

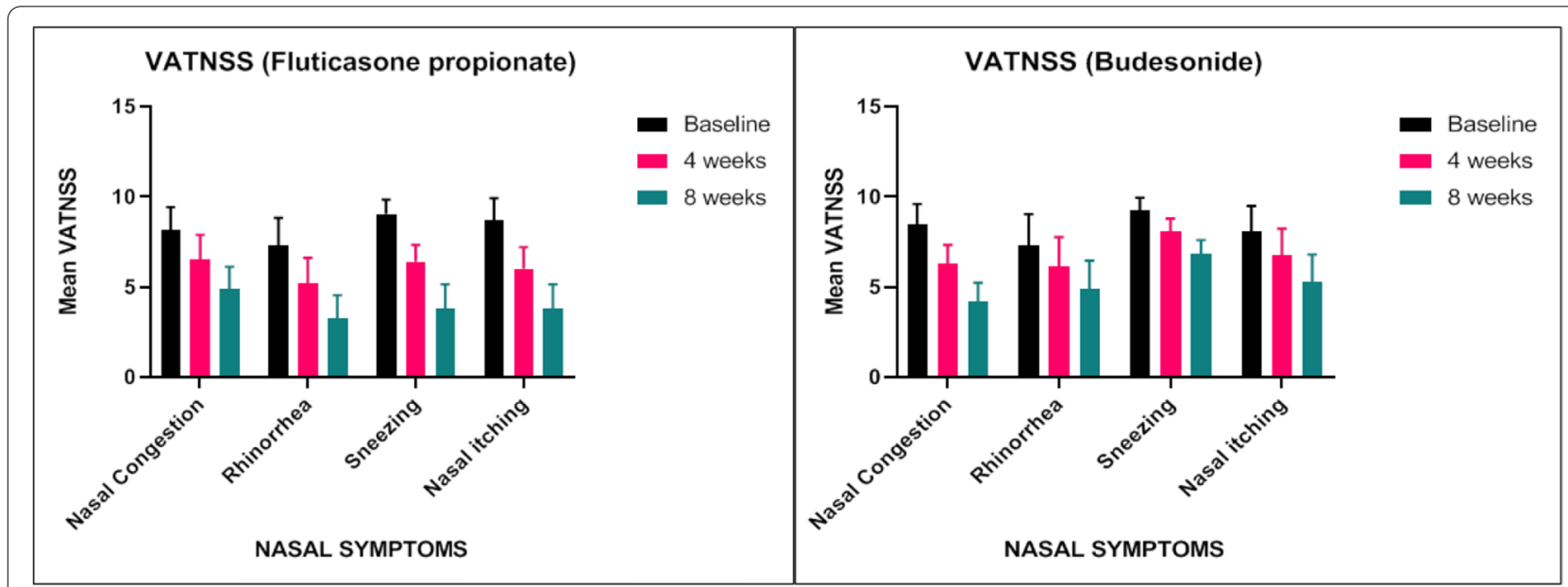

Fig. 2 A Comparison of total nasal symptoms scores at baseline, 4th and 8th week in patients treated with Fluticasone propionate. B Comparison of total nasal symptoms scores at baseline, 4th and 8th week in patients treated with Budesonide 


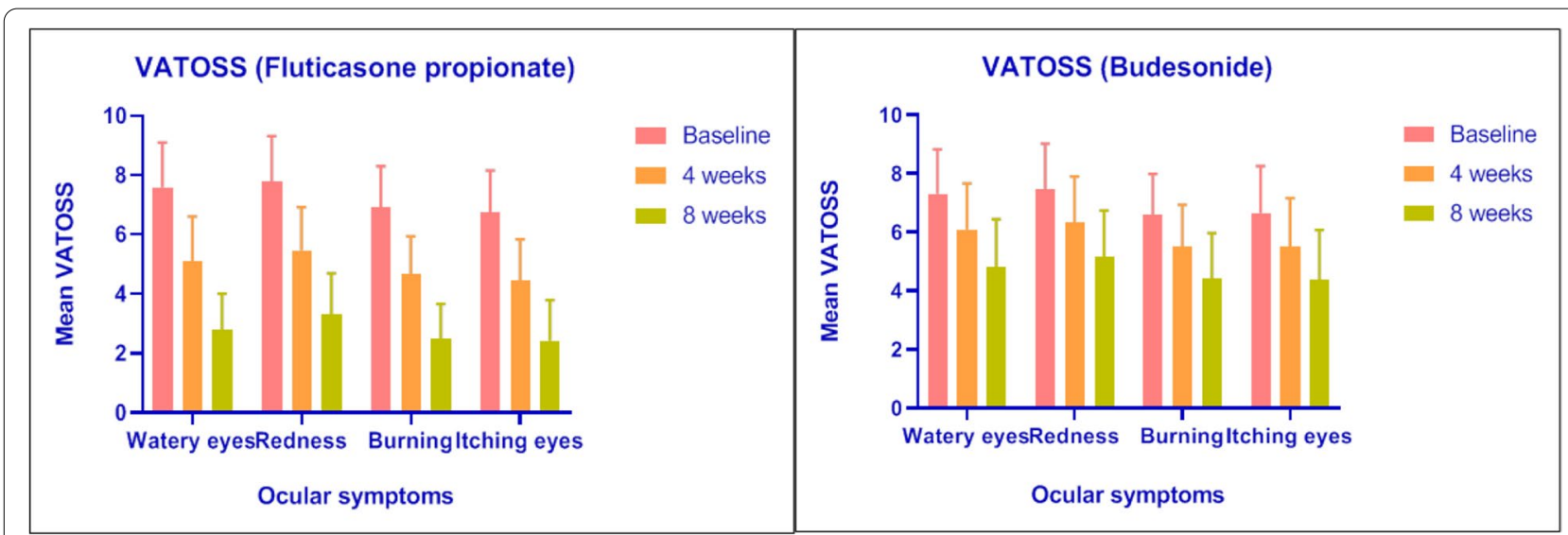

Fig. 3 A Comparison of total ocular symptoms scores at baseline, 4th and $8^{\text {th }}$ week in patients treated with Fluticasone Propionate. B Comparison of total ocular symptoms scores at baseline, 4th and 8th week in patients treated with Budesonide

\section{Visual analogue total nasal symptom score}

Comparing the mean difference in nasal symptom scores between fluticasone propionate and budesonide during 8 weeks of treatment, FUP shows faster onset of action and statistically significant when compared to budesonide (Table 2).

During the first 4weeks of treatments, FUP significantly reduced the VATNSS compared with BUD. In terms of individual symptoms, FUP was significantly more effective than budesonide at reducing sneezing and nasal itching

Table 3 Efficacy outcomes of visual analogue total ocular symptom scores

\begin{tabular}{lllll}
\hline Characteristics & & FUP $(\boldsymbol{n}=\mathbf{3 0})$ & BUD $(\boldsymbol{n}=\mathbf{3 2})$ & $\boldsymbol{P}$ value \\
\hline VATOSS & & & & \\
Watery eyes & Baseline & $7.59 \pm 1.51$ & $7.30 \pm 1.53$ & 0.45 \\
& 4th week & $5.09 \pm 1.51$ & $6.09 \pm 1.57$ & 0.01 \\
& 8th week & $2.80 \pm 1.22$ & $4.80 \pm 1.64$ & $<0.0001$ \\
& P value & $<\mathbf{0 . 0 0 0 1}$ & $<\mathbf{0 . 0 0 0 1}$ & \\
Redness & Baseline & $7.78 \pm 1.54$ & $7.47 \pm 1.55$ & 0.43 \\
& 4th week & $5.46 \pm 1.46$ & $6.31 \pm 1.59$ & 0.03 \\
& 8th week & $3.32 \pm 1.37$ & $5.14 \pm 1.60$ & $<0.0001$ \\
& P value & $<\mathbf{0 . 0 0 0 1}$ & $<\mathbf{0 . 0 0 0 1}$ & \\
Burning & Baseline & $6.90 \pm 1.40$ & $6.60 \pm 1.39$ & 0.4 \\
& 4th week & $4.67 \pm 1.26$ & $5.49 \pm 1.44$ & 0.02 \\
& 8th week & $2.49 \pm 1.18$ & $4.43 \pm 1.53$ & $<0.0001$ \\
& P value & $<\mathbf{0 . 0 0 0 1}$ & $<\mathbf{0 . 0 0 0 1}$ & \\
Itching eyes & Baseline & $6.73 \pm 1.42$ & $6.65 \pm 1.60$ & 0.83 \\
& 4th week & $4.44 \pm 1.40$ & $5.50 \pm 1.66$ & 0.008 \\
& 8th week & $2.43 \pm 1.37$ & $4.38 \pm 1.69$ & $<0.0001$ \\
& P value & $<\mathbf{0 . 0 0 0 1}$ & $<\mathbf{0 . 0 0 0 1}$ & \\
\hline
\end{tabular}

Data are shown as mean \pm standard deviation as appropriate. Unpaired $T$ test was used to determine significance

VATOSS Visual Analogue Total Ocular Symptom Score, FUP Fluticasone propionate, BUD Budesonide throughout the 8 weeks of treatment, and also significantly more effective in alleviating sneezing, rhinorrhea and nasal itching during 8 weeks of treatment $(P<0.001)$. The reduction in symptom scores for nasal blockage was similar in the FUP and BUD groups during weeks 1-8 (Fig. 2A, B).

\section{Visual analogue total ocular symptom scores}

Mean and standard deviation differ in ocular symptom scores between fluticasone propionate and budesonide during 8 weeks of treatment. During 8 weeks of treatment, FUP significantly reduced the VATOSS when compared with BUD. In terms of individual symptoms, FUP was significantly more effective than budesonide at reducing redness, burning, itching eyes and watery eyes throughout the 8 weeks of treatment (Fig. 3A, B).

The changes in FUP group were significantly greater than budesonide during weeks $1-4(P<0.0001)$ and weeks 4-8 $(P<0.0001)$. However, BUD group also showed significant difference of ocular symptoms from baseline to 8 weeks but BUD group shows less efficacy and onset of action when compared with FUP group (Table 3).

\section{Eosinophil counts}

In FUP group, the mean $\pm S D$ of eosinophil count at baseline was $917.06 \pm 249.14$ and decreased to $917.06 \pm 249.14$ and $418.23 \pm 88.60$ at 4 th and 8 th week of treatment respectively, which shows statistically highly significant. In BUD group, the mean $\pm S D$ of eosinophil count at baseline was $904.37 \pm 244.79$ and slightly reduced to $777.31 \pm 231.48$ and $606.15 \pm 166.53$ at 4th and 8th week of treatment respectively (Table 4).

Mean reduction of eosinophil count from baseline over 8-week treatment period in both the group. Both Fluticasone propionate and budesonide showed statistically significant decrease in eosinophil count but 
Table 4 Outcomes of eosinophil count

\begin{tabular}{lllll}
\hline Characteristics & & FUP $(\boldsymbol{n}=\mathbf{3 0})$ & BUD $(\boldsymbol{n}=\mathbf{3 2})$ & $\boldsymbol{P}$ value \\
\hline Eosinophil count cells $/ \boldsymbol{\mu L}$ & Baseline & $917.06 \pm 249.14$ & $904.37 \pm 244.79$ & 0.84 \\
& 4th week & $655.26 \pm 186.59$ & $777.31 \pm 231.48$ & 0.02 \\
& 8th week & $418.23 \pm 88.60$ & $606.15 \pm 166.53$ & $<0.0001$ \\
& $\boldsymbol{P}$ value & $<0.0001$ & $<0.003$ &
\end{tabular}

Data are shown as mean \pm standard deviation as appropriate

FUP Fluticasone propionate, BUD Budesonide

Unpaired $T$ test was used to determine significance

fluticasone showed faster onset of action and greater immunologic improvement compared to budesonide. Hence, fluticasone propionate was found to be more efficacious than budesonide in reducing eosinophil counts (Fig. 4).

\section{Discussion}

Allergic rhinitis or Hay fever is a chronic inflammation of the nasal mucosa induced by IgE-mediated hypersensitivity due to exposure of various allergens such as pollen, mold, animal dander, dust, mites, etc. AR occurs as a response against inhaled allergens that causes inflammation of nasal mucosal membranes [17].

The present study was carried out to assess the reduction in severity of symptoms and inflammatory cells in allergic rhinitis patients by comparing the intranasal corticosteroids such as Fluticasone propionate and Budesonide. The results of our comparative study demonstrate that Fluticasone propionate regularly once daily is more effective for the treatment of nasal and ocular symptoms in patients with allergic rhinitis than budesonide. This was proven by the study conducted by Lorenzo. G. D et al., which concluded that Fluticasone propionate administered monotherapy prevents eosinophil increase in nose during pollen season as measured in nasal lavage, whereas the use of mediator antagonists in combined therapy failed to produce [18].

A study conducted by Dellon E. S et al. concluded that a randomized clinical trial, initial treatment of Eosinophilic Esophagitis (EoE) with either oral viscous budesonide (OVB) or fluticasone multi dose inhaler (MDI) produced a significant decrease in esophageal eosinophil counts and improved dysphagia and endoscopic features [19]. Study by Tai C. J et al. has concluded that the patients with moderate to severe allergic rhinitis in patients who are sensitive to specific allergens during well define pollination season can

\section{Absolute Eosinophil Count}

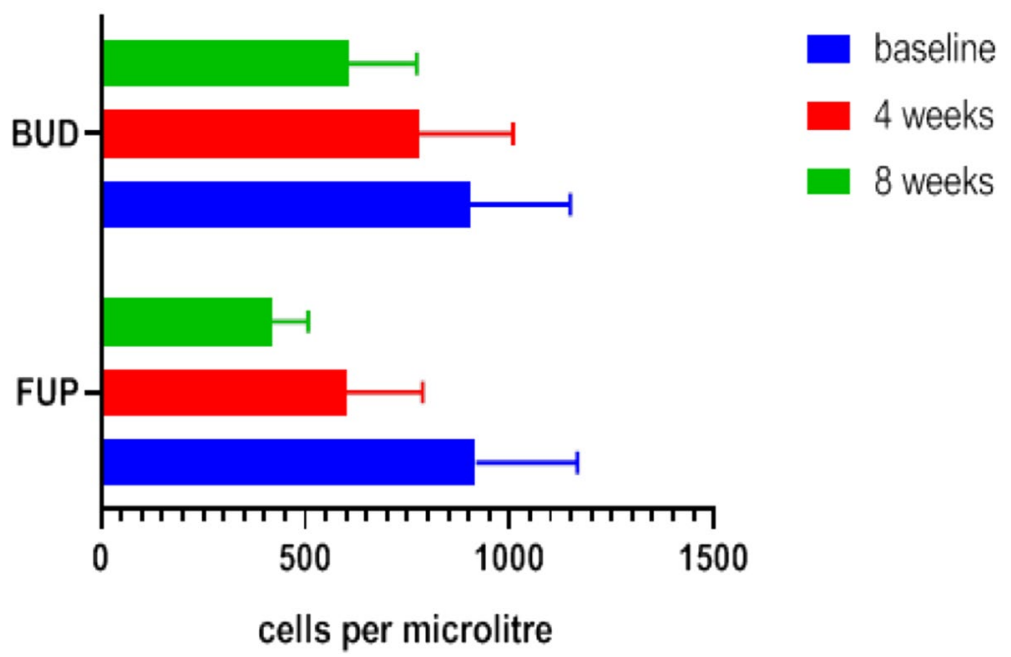

Fig. 4 A Comparing the efficacy of intravitreal ranibizumab from baseline to 6 months in reducing central foveal thickness. B Comparing the efficacy of intravitreal triamcinolone from baseline to 6 months inreducing central foveal thickness 
provide greater immunologic effect by reducing serum IgE reaction to allergens [20]. The study on Allergic Rhinitis and its Impact on Asthma (ARIA) guidelines 2016 revision by Brozek J. L has recommended the measures of allergic rhinitis control using symptom scores, VAS Scores, quality of life scores and other several items. Using these recommendations, our study was carried out using VAS scores for assessing the severity of symptoms [21].

Recent study in allergy article by ARIA and European Academy of Allergology and Clinical Immunology (EAACI) proposed a questionnaire by Dutch ENT society to ARIA members all over the world. In the results of those questionnaire, $91.6 \%$ members of ARIA agreed to the question "currently nasal corticosteroid spray can be continued in hay fever season." Hence, studies on intranasal corticosteroids can help in the current situation of Covid-19 patients with allergic rhinitis [22].

\section{Conclusion}

Based on the above results, it is concluded that Fluticasone propionate therapy showed statistically significant benefits such as reduced Eosinophil counts and nasal and ocular symptoms when compared to Budesonide therapy. In addition, fluticasone propionate had a faster onset of action compared to budesonide in reducing eosinophil counts which were stimulated by IgE-mediated inflammatory cytokines. Hence, it is an effective treatment than budesonide in reducing sneezing, itching, rhinorrhea, ocular symptoms, and increased eosinophil counts of allergic rhinitis patient, reflecting its more potent topical anti-inflammatory activity.

\section{Limitations of the study}

The main limitation of this study is that less number of patients included in the study and due to short period of study, side effects of the drug cannot be assessed and recurrence of the disease cannot be noted.

\section{Abbreviations \\ AR: Allergic rhinitis; BUD: Budesonide; FUP: Fluticasone propionate; IgE: Immunoglobulin E; VATNSS: Visual Analogue Total Nasal Symptom Scores; VATOSS: Visual Analogue Total Ocular Symptom Scores; VAS: Visual analogue scale; ANOVA: Analysis of variance; EoE: Eosinophilic esophagitis; OVB: Oral viscous budesonide; MDI: Multi dose inhaler; ARIA: Allergic Rhinitis and its Impact on Asthma; EAACl: European Academy of Allergology and Clinical Immunology.}

\section{Acknowledgements}

We acknowledge the ESIC Hospital doctors, nurses, and other health care professionals who helped in the study and all the patients who were enrolled in the study after informed consent is obtained.

\section{Authors' contributions}

SS made the contributions in conception and design in conducting the study and approved the manuscript. PKS performed the study and drafted and revised the manuscript for intellectual content. RFB gave technical inputs in the acquisition of data and analysis. All authors have read and approved the final manuscript.

\section{Funding}

No funding was received through any funding agencies towards carrying this research work.

\section{Availability of data and materials}

Data and material are available upon request.

\section{Declarations}

\section{Ethics approval and consent to participate}

The protocol of this study was revised and approved by the Institutional Ethics Committee, VELS Institute of Science, Technology and Advanced Studies, Chennai, India- 600117. Written informed consent was obtained from each of the study participants after briefing them about the study and that the obtained data will be published.

\section{Consent for publication}

Consent was obtained from the patients participated in the study for the publishing of the data obtained during the study.

\section{Competing interests}

The authors declare no competing interests.

\section{Author details}

'Department of Pharmacy Practice, School of Pharmaceutical Sciences, Vels Institute of Science, Technology and Advanced Studies (VISTAS), Pallavaram, Chennai, Tamil Nadu, India. ${ }^{2}$ Department of Pharmacology, SRM College of Pharmacy, SRM Institute of Science, and Technology, Kattankulathur, Chennai, Tamil Nadu, India.

Received: 23 June 2021 Accepted: 22 October 2021

Published online: 27 November 2021

\section{References}

1. Schuler CF, Montejo JM (2019) Allergic rhinitis in children and adolescents. Pediatr Clin 66:981-993

2. Kivisaari E, Baker R C, Price M J (2001) Comparison of once daily fliticasone propionate aqueous nasal spray with once daily budesonide reservoir powder device in patients with perennial rhinitis. Clinical and experimental allergy 31:855-863

3. Kar M, Muluk NB, Bafaqeeh SA, Cingi C (2019) Condensus on the methodology for experimental studies in allergic rhinitis. Int J Pediatric Otolaryngology 121:68-71

4. Kakli HA, Riley TD (2016) Allergic rhinitis. Clinics in Office Practice 43:465-475

5. Bousquet J, Cauwenberge PV (2002) Allergic rhinitis and its impacts on asthma (ARIA) in collaboration with the World Health Organisation. Prim Care Respir Med 11:18-19

6. Bedard A, Basagana X, Anto JM, Aymerich JG, Devillier P, Arnavielhe S et al (2019) Mobile technology offers novel insights into the control and treatment of allergic rhinitis: the MASK study. J Allergy Clin Immunol 144:135-143

7. Emeryk A, Maksymiuk E J, Janeczek K (2019) New guidelines for the treatment of seasonal allergic rhinitis 36:255-260

8. Bousquet J, Khaltaev N, Cruz A, Denburg J, Fokkens WJ, Togias A et al (2008) Allergic rhinitis and its impacts on asthma (ARIA) 2008. Allergy 63:8-160 
9. Wang X, Du K, She W, Ouyang Y, Sima Y, Liu C et al (2018) Recent advances in the diagnosis of allergic rhinitis. Expert Rev Clin Immunol 14:957-964

10. Trangsrud AJ, Whitaker AL, Small RE (2002) Intranasal corticosteroids for allergic rhinitis. The Journal of Human Pharmacology and Drug Therapy 22:1458-1467

11. Berg NJ, Darling P, Bolvig J, Skiftesvik MH, Halken S, Winther L et al (2017) Intranasal corticosteroids compared with Oral antihistamines in allergic rhinitis: a systematic review and meta-analysis. American Journal of Rhinology and Allergy 31:e19-e28

12. Berger W, Bousquet J, Fox AT, Just J, Muraro A, Neito A et al (2016) MP AzeFlu is more effective than fluticasone propionate for the treatment of allergic rhinitis in children. Allergy 71:1219-1222

13. Kariyawasam HH, Scadding $\mathrm{GH}$ (2010) Seasonal allergic rhinitis : fluticasone propionate and fluticasone furate therapy evaluated. J Asthma and Allergy 3:19-28

14. Chen H, Lou H, Wang Y, Cao F, Zang L, Wang C (2018) Comparison of the efficacy and mechanisms of intranasal budesonide, montelukast, and their combination in treatment of patients with seasonal allergic rhinitis. International Forum of Allergy and Rhinology 8:1242-1252

15. Klimek L, Bergmann KC, Biedermann T, Bousquet J, Hellings $P$, Jung $K$ et al (2017) Visual analogue scales (VAS): measuring instruments for the documentation of symptoms and therapy monitoring in cases of allergic rhinitis in everyday health care. Allergo J Int 26:16-24

16. Sybilski AJ (2018) Visual analogue scale. A simple tool for daily treatment monitoring in allergic rhinitis. Pediatr Med Rodz 14:277-281
17. Seidman MD, Gurgel RK, Lin SY, Schwartz SR, Baroody FM, Bonner JR et al (2015) Clinical practice guideline: allergic rhinitis. Otolaryngology- Head and Neck surgery 152:s1-s43

18. Lorenzo GD, Gervasi F, Drago A, Pellitteri ME, Salvo AD, Cosentino D et al (1999) Comparison of the effects of fluticasone propionate, aqueous nasal spray and Levocabastine on inflammatory ceels in nasal lavage and clinical activity during the pollen season in seasonal rhinitis. Clinical Experimental Allergy 29:1367-1377

19. Dellon ES, Woosley JT, Arrington A, McGee SJ, Covington J, Moist SE et al (2019) Efficacy of budesonide vs fluticasone for initial treatment of Eosinophilic esophagitis in a randomized controlled trial. Gastroenterology 157:65-73

20. Tai CJ, Wang PC (2003) Comparison of two intranasal corticosteroids in treating allergic rhinitis. Otolaryngology- Head and Neck surgery 129:518-525

21. Brozek JL, Bousquet J, Agache I, Agarwal A, Bachert C, Anticevich SB et al (2017) Allergic rhinitis and its impacts on asthma (ARIA) guidelines-2016 revision. J Allergy Clin Immunol 140:950-958

22. Bousquet J, Akdis C, Jutel M, Bachert C, Klimek L, Agache L et al (2020) Intranasal corticosteroids in allergic rhinitis in COVID-19 infected patients: an ARIA-EAACI statement. Allergy

\section{Publisher's Note}

Springer Nature remains neutral with regard to jurisdictional claims in published maps and institutional affiliations.

\section{Submit your manuscript to a SpringerOpen ${ }^{\circ}$ journal and benefit from:}

- Convenient online submission

- Rigorous peer review

- Open access: articles freely available online

- High visibility within the field

- Retaining the copyright to your article

Submit your next manuscript at $\boldsymbol{\nabla}$ springeropen.com 